\title{
Cross-cultural Adaptation and Validation of Patient Safety Culture Assessment Tool for Clinical Staff in Kazakhstan
}

\author{
Kyrykbayeva Saltanat ${ }^{1 \star}$, Semenova $\mathrm{Yu}^{1}$, Goremykina $\mathrm{M}^{1}$, Moldagaliyev $\mathrm{T}^{1}$, Kauysheva $\mathrm{A}^{2}$, Azizov $\mathrm{Sh}^{3}$, Trinchero $\mathrm{E}^{4}$ \\ ${ }^{1}$ Semey Medical University, Semey, Kazahstan Republic; ${ }^{2}$ Kazakhstan's Medical University “KSPH”, Almaty, Kazakhstan \\ Republic; ${ }^{3}$ Urology Research Centre, Almaty, Kazakhstan Republic; ${ }^{4}$ SDA Bocconi School of Management, Milan, Italy
}

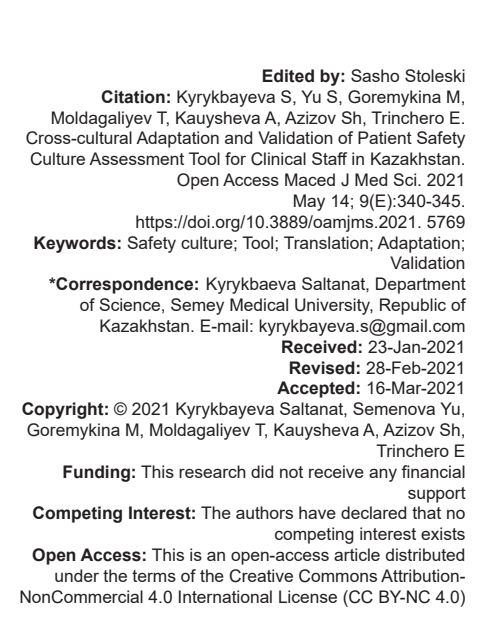

Abstract

BACKGROUND: Modern healthcare systems lack empirical models and appropriate tools to evaluate the safety culture, which encourages the need for their development.
empirically tested robust tools to evaluate the safety culture.

AIM: The present paper aims at performing translation, cross-cultural adaptation, and validation of the "Patient safety culture" tool (from here - the tool) as a means for evaluating safety culture in healthcare establishments of the Republic of Kazakhstan.

METHODS: The study design was cross-sectional. The original "Patient safety culture" tool is an integrated evaluation framework consisting of 7 scales and 62 items ( 6 general questions and 56 targeted questions) and reflecting different aspects of risk-related components of safety culture. The Cronbach's alpha coefficient ranging from 0.0 to 1.0 was used to measure the internal consistency of the tool. To evaluate the tool's reproducibility, we performed a test-retest assessment after 15 days and evaluated it using Pearson's correlation coefficient.

RESULTS: The overall Cronbach's alpha for different scales ranged from 0.27 to 0.75 . Subscales "Safety procedures" and "Safety Training" had the lowest coefficients. At test-retest, the Pearson's correlation coefficient ranged from 0.934 to 0.969 among the scales.

CONCLUSION: The study is dedicated to cross-cultural adaptation and validation of the "Patient safety culture" tool and describes the development of a translation protocol with subsequent cognitive debriefing and field testing The field testing helped to confirm good validity, reliability, and reproducibility. The tool might undergo additiona modification after further testing.

\section{Introduction}

The safety culture is one of the most important in the modern medical institution because any problems in the provision of services can lead to irreversible consequences. Not only the patient may suffer but also the doctor who renders assistance. In the post-Soviet countries, including Kazakhstan, increasingly greater attention is paid to the culture of patient safety in medical organizations.

Globally, health systems are challenged to apply empirical models and related tools to assess safety culture, which is driving the need for their development [1]. It is important to lay grounds for the identification of safety risks from medical personnel and patients to improve the quality of medical aid at all levels of the healthcare system [2]. As clinical risks cannot be eliminated completely, systematic interventions have to be envisaged to protect patients from possible risks by means of mitigation and control measures, including through an assessment of the safety culture [3].

As reported by the Institute of Medicine, the majority of clinical risks arise directly from shortcomings and deficiencies in the healthcare system [4]. Since the system, along with its processes, is responsible for shaping the environment leading to errors, such a system has to establish a safety culture, which means that substantial efforts have to be made to manage risk factors [5]. One of the ways to solve this problem is to establish the risk management system with the safety culture underpinned in the common culture of the organization [6].

Risk management is the term that first appeared after the Chernobyl Nuclear Accident and nowadays, it is broadly used in the oil and gas industry, in transport, aviation, and military system. There is an abundance of literature demonstrating associations between safety culture and safety indicators in organizations from different sectors [7], [8], [9]. Constructive safety culture is crucial for enhanced patient safety in any medical establishment [2]. Comprehensive, reliable, and effective models for evaluation of safety culture in a healthcare facility can be used to generate evidence of improved patient outcomes [10], [11], [12], [13].

For the past decade of years, the process of aligning the healthcare system of Kazakhstan to international standards has been escalated. Nowadays, Kazakhstan comes across the initial stage of creating a patient safety culture. New accreditation standards for 
hospitals acquired from international experience were introduced in the Kazakhstani medical practice in 2018. In its development, the Kazakhstan model of standardization of medical activities is oriented toward the Joint Commission International $(\mathrm{JCl})$ model that recognized in many countries.

According to the requirements set by the $\mathrm{JCl}$, safety culture should be evaluated by a medical establishment on a regular basis using different methods [14].

Meanwhile, the national healthcare system has no empirically tested robust tools to evaluate the safety culture [15]. The early proposed version of the tool for assessing patient safety culture has not been published in Kazakhstan in the official and Russian languages and therefore has not been widely spread.

Therefore, there is a discrepancy between the modern requirements to evaluate safety culture and the current situation, which justifies the need for adaptation of existing international tools. Up to this point, hardly anything is aware of the conditions of safety culture in Kazakhstan's medical organizations. This assessment on the part of leaders can provide meaningful data to manage the risks in health care organizations.

This research of patient safety culture was conducted from August to October 2018 using a questionnaire about the attitudes to safety in Russian and Kazakh languages. The objectives of this research were to study the reliability and validity of the questionnaire in the Russian language to assess attitudes to safety and establish control data on the safety culture in Kazakhstan's health care. In this publication, we give an account of the Russian version of the tool.

Our study is aimed at performing translation, cross-cultural adaptation, and validation of the "Patient safety culture" tool (from here - the tool) as a means for evaluating safety culture in healthcare establishments of the Republic of Kazakhstan. Applying the method of stratified random sampling, we investigated the departments of a large clinic that provides medical and sanitary and consultative diagnostic care at the outpatient level. Medical personnel in each department participated in the survey on a voluntary basis

The internal consistency and reliability were tested through Cronbach's alpha, whereas the questionnaire's structural validity was tested using correlation analysis and confirmatory factor analysis (CFA). The patient safety culture was assessed and analyzed in the five hospitals.

\section{Methods}

\section{Original tool}

The original tool is an integrated evaluation framework, which consists of 7 scales and 62 items (6 general questions and 56 targeted questions) and reflects different aspects of risk-related components of safety culture. The scale "Safety leader-member exchange" (Safety LMX) is composed of 10 questions, the scale "Engagement" (EE) has 9 questions, the scale "Safety procedures" (SPRO) consists of 4 questions, and the scale "Safety Training" (ST) comprises 5 questions. The scale "Safety Priorities" (SPRI) constitutes 4 questions, the scale "Safety behaviors" (SB) is constructed of 12 questions, and the scale "Psychological Capital" (PsyCap) is built of 12 questions. All answers are based on a 6-point Likert scale, ranging from "completely disagree" to "completely agree [1]." General hypothesis: The questionnaire is valid for the Russian-speaking sample.

\section{Translation-retrans/ation}

Following international principles of good practice for translation and cross-cultural adaptation [16], the PSC was obtained from the developers [1] and translated into Russian by two bilingual translators, one of whom is a co-author of this manuscript and is a public health specialist familiar with the topic (T1). The second translator was a "native translator" (i.e., blinded to the purpose of translation) and is a professional teacher of English language (T2). The meeting of two translators was held to discuss inconsistencies and introduce amendments into Russian version of the tool with the subsequent synthesis of both versions.

As a next step, two independent translators whose first language was English and who had no access to the English version of the tool retranslated the revised Russian version into English for the last check. Independent teacher of English language was invited to compare the English translation with the original version of the tool. Emphasis was made on conceptual and cultural equivalence but not linguistic equivalence. Discrepancies were discussed until a satisfactory version of the tool was reached.

\section{Expert committee and pre-final testing}

A meeting of a multidisciplinary expert committee consisting of a safety culture specialist, two hospital managers, a psychologist, and one of the translators (T2) was held to discuss the obtained version of the tool. Expert panel reviewed the tool using content validity indexing (CVI). CVI involved scored feedback from all experts who evaluated if the question was appropriate and relevant to the study population, if the format of the question was appropriate, and offered suggestions for improvement. The entire tool was thoroughly analyzed and nonconformities between specialists were discussed to achieve a consensus.

After this version of the tool was constructed, it has undergone pre-final testing by a group of ten medical professionals concerning the safety culture. Besides the tool's administration, respondents were 
also systematically debriefed. This debriefing was related to what they thought the question was asking, whether they could repeat the question in their own words, what came to their mind when they heard a particular phrase or term. During the debriefing, the respondents were also asked to explain how they chose their answer. At the end, they were asked about the overall content and structure of the tool. The answers to these questions were compared to the respondents' actual responses to the instrument for consistency. The respondents were also asked about any word they did not understand as well as any word or expression that they found unacceptable or offensive.

A written report of all the steps was provided. Another meeting of a multidisciplinary expert committee was held to discuss the gathered opinions, which helped to adopt the final version of the tool for further use without amendments.

\section{Study population}

One hundred and two healthcare professionals working in hospital in the university hospital in Semey, Kazakhstan Republic were invited to participate in the study, 95 of whom agreed and returned the completed questionnaires, which resulted in $93.1 \%$ response rate. The sample group included medical doctors, nurses, and members of managerial and support staff. For the purpose of re-testing, the tool was repeatedly sent to the same 95 participants two weeks later, and 82 professionals returned the completed form $(86.3 \%$ response rate). All test-retest procedures took place in June 2018. The only exclusion criterion applied was a refusal to participate in the study. The data from incomplete questionnaires were not analyzed.

\section{Statistical analysis}

The Cronbach's alpha coefficient ranging from 0.0 to 1.0 was used to measure internal consistency of the tool. Higher values are associated with higher internal consistency, while the cut-off point equal to or exceeding 0.7 was used to consider the test reliable [17]. To evaluate reproducibility of the tool, we performed a test-retest assessment after 15 days and evaluated it using Pearson's correlation coefficient. Higher values of the test were considered to be associated with higher reproducibility and were indicative for unambiguous understanding of questions by the respondents. For our purposes, the following thresholds were accepted: $r \geq 0.7$ as high, 0.61-0.69 as moderately high, 0.41-0.6 as moderate, and $0-0.4$ as poor [18]. The comparison with other tools was not applied since there is no other established tool in Russian to measure the safety culture.

To investigate the correctness of collected data and whether the factor structure of the scale model fit that data, the CFA was applied. The constructed structural equation model was used to explore whether the index variable could be effectively used as a measure of the factors. The missing value was sidelined by the average near points in the CFA but maintained null values in other statistical analyses.

Statistical tests were conducted using IBM SPSS Statistics software ("Statistical Package for the Social Sciences") version 20.0 (IBM Corp., Armonk, NY, USA) and $p<0.05$ were considered as statistically significant.

\section{Ethical approval}

Ethical approval was obtained from the Ethics Committee of Semey Medical University (Protocol No. 5 dated 9 of April, 2018) before starting the procedure.

\section{Results}

\section{Cross-cultural adaptation of the tool}

In general, the stages of translation-retranslation and synthesis went rather smooth. However, certain amendments were introduced into the tool. For example, third item of the safety component of supervisor-employee relationship was modified to replace future tense by present tense, which was considered to be more relevant in this context. Besides, some amendments were made to make the tool more idiomatically equivalent. For example, the term "procedures" was replaced by the term "instructions" in three out of four items of the "Safety procedures" scale. Errors related to reading or interpretation were identified in $25 \%$ of items in the "Safety behaviors" scale and in $16.6 \%$ of items in the "Psychological Capital" scale, after which more relevant lexical interpretations were selected. Furthermore, respondents engaged in pre-final testing pointed out at a number of items that could be difficult to understand. For example, items SLMX 3 and SLMX 4 were very similar and only differed in a few words, which were fundamental for understanding their meaning. The expert committee expressed a wish to emphasize the differing details in these items.

Most of the study participants $-93.6 \%$ (89 out of $95)$ believed that the tool provides very clear instructions and $86.6 \%$ (82 out of 95 ) reported no difficulties in filling in the questionnaire. Meanwhile, $96.6 \%$ (91 out of 95) study participants informed about good understanding of the questions. The mean time for filling in the questionnaire was $9.5 \mathrm{~min}(\mathrm{SE}=1.12)$, minimal testing time was $7.5 \mathrm{~min}$, and maximal testing time was $12 \mathrm{~min}$.

\section{Testing reliability and reproducibility}

Out of 102 healthcare professionals invited, $95(93.1 \%)$ agreed to participate and returned fully completed questionnaires. The vast majority of healthcare 
professionals recruited into the study were females and the male:female ratio was $1: 6$, which is consistent with the current gender structure of Kazakhstani medical workforce. Most of healthcare professionals interviewed were medical doctors (70\%) followed by nurses $(23.3 \%)$ and managerial or support staff $(6.7 \%)$ - Table 1.

Table 1: Demographic and professional profile of study participants

\begin{tabular}{lll}
\hline Variables & Test & Retest \\
\hline Number of fully completed questionnaires & $95(93.1 \%)$ & $82(86.3 \%)$ \\
Age & $43.39(41.2 ; 45.6)$ & $44.4(41.4 ; 47.1)$ \\
Male: Female ratio & $1: 6$ & $1: 6.2$ \\
Specialists & $23(24.2 \%)$ & $20(23.2 \%)$ \\
General practitioners & $6(6.3 \%)$ & $6(7.3 \%)$ \\
Nurses & $49(51.6 \%)$ & $46(56.1 \%)$ \\
Managers & $3(3.1 \%)$ & $2(2.4)$ \\
Other professionals - IT, technicians, statisticians & $14(14.8 \%)$ & $8(11 \%)$ \\
\hline
\end{tabular}

As a measure of internal consistency, the Cronbach's alpha coefficient was 0.746 and the reliability coefficient of Spearman-Brown $\left(r_{\text {sb }}\right)$ was 0.748 . Table 2 presents the evaluation of test reliability based on the interitem correlation and the Cronbach's alpha coefficient.

Table 2: Results of the test reliability among study participants $(n=95)$

\begin{tabular}{llll}
\hline Item & $\begin{array}{l}\text { Inter-item } \\
\text { correlation }\end{array}$ & $\begin{array}{l}\text { Cronbach's } \\
\text { alpha }\end{array}$ & $\begin{array}{l}\text { Standardized } \\
\text { Cronbach's alpha }\end{array}$ \\
\hline $\begin{array}{l}\text { Safety leader-member } \\
\text { exchange (Safety LMX) }\end{array}$ & 0.16 & 0.63 & 0.65 \\
$\begin{array}{l}\text { Engagement (EE) } \\
\text { Safety procedures (SPRO) }\end{array}$ & 0.32 & 0.81 & \\
Safety training (ST) & 0.02 & 0.27 & 0.81 \\
Safety priorities (SPRI) & 0.1 & 0.30 & 0.31 \\
Safety behaviors (SB) & 0.1 & 0.41 & 0.33 \\
Psychological Capital (PsyCap) & 0.16 & 0.65 & 0.69 \\
Overall & 0.20 & 0.75 & 0.75 \\
\hline
\end{tabular}

The results of test-retest evaluation for different scales of the tool are presented in Table 3. In general, the tool showed high reproducibility, which shows the adequate perception and understanding of all questions by the study participants. The ICC coefficient in the study of the reproducibility of the scale by the test-retest method is considered high at values of 0.9 and more (in our study - 0.95).

Table 3: Results of the test-retest reliability among study participants $(n=82)$

\begin{tabular}{lll}
\hline Item & ICC & Sig. (p) \\
\hline Safety leader-member exchange (Safety LMX) & 0,944 & 0.0001 \\
Engagement (EE) & 0.953 & 0.0001 \\
Safety procedures (SPRO) & 0.952 & 0.0001 \\
Safety training (ST) & 0.934 & 0.0001 \\
Safety priorities (SPRI) & 0.969 & 0.0001 \\
Safety behaviors (SB) & 0.957 & 0.0001 \\
Psychological capital (PsyCap) & 0.952 & 0.0001 \\
\hline
\end{tabular}

The last meeting of the expert committee was held to discuss the results of the tool's testing and to adopt the final version. It was decided to leave the number of items and their content the same as in the pre-final version but to introduce minor adjustments.

\section{Discussion}

Safety culture becomes increasingly important for modern medical practice as it directly affects many aspects of medical care, including patient satisfaction [19], [20]. In fact, safety culture could be considered as a set of values, attitudes, perceptions, competencies, and behaviors that define the commitment, style, and competence of an individual medical professional or a group of medical professionals in ensuring patient safety [21]. This includes how managers and professionals act to improve health care, for example, through collective learning and error correction. Still, strategies developed to promote a safety culture of safety have not been widely adopted in primary health care [1]. Instruments that assess patient safety are important for evaluation of organizational conditions that lead to medical accidents, and thus, they contribute to safety awareness. This type of evaluation helps diagnose factors that influence the safety culture and patient safety [8]. As Kazakhstani practice lacks instruments to evaluate safety culture, the cross-cultural adaptation and validation of internationally recognized tool could be considered as timely and appropriate.

The "Patient safety culture" tool is a relatively new tool built of separate scales and it had never undergone cross-cultural adaptation and validation earlier. For this reason, we are unable to compare the findings of the present study with the findings of other studies on the same tool. Nevertheless, our findings could be compared with the results of the evaluation of other tools measuring the patient safety culture.

Other researchers reported unsatisfactory values of Cronbach's alpha in separate sub-scales of different tools on patient safety culture [22], [23]. In our study, the lowest values of Cronbach's alpha were observed in "Safety procedures" and "Safety training" scales. This could be due to slightly different interpretation of some items because of specific national characteristics. Although the "Safety procedures" and the "Safety training" scales showed rather low reliability, most of the items were found to be valid, which means that the tool has acceptable psychometric properties.

The tool's reliability was assessed based on Cronbach's alpha. Still, it has to be noted that only repeated use of the tool in various settings could confirm its validity and reliability. In other words, we can only be certain that the scale is reliable if it generates reliable data on a regular basis [24]. With regard to the reproducibility, the adapted version of the tool presents the Pearson's correlation coefficient ranging from 0.934 to 0.969 among the scales that are more than satisfactory.

However, there are certain limitations of this study. First, the sample size was rather small and all study participants originated from the same medical setting. To overcome this disadvantage, we applied the random sampling method to recruit healthcare professionals in the test-retest study. The second disadvantage comes from the fact that linguistic validation and cross-cultural adaptation allowed to introduce only minor changes and amendments to the original version. 
We believe that the results of cross-cultural adaptation and validation of the "Patient safety culture" tool are very satisfactory and that the adapted tool may be used to monitor the safety culture in healthcare establishments of Kazakhstan. The semantic, idiomatic, experiential, and conceptual equivalence between the original version and the Russian version were assessed and field testing helped to confirm good validity, reliability, and reproducibility with only a few exceptions. The tool might undergo additional modification after further testing. We are planning to administer the tool to the target population of healthcare professionals in the course of the main study so that the psychometric properties of the tool could be further verified. We hope that healthcare professionals working in other Russianspeaking countries will find it helpful.

The limitations of this study, in our opinion, are that Kazakhstani medical organizations do not yet have a sufficient and informed understanding of the importance of assessing safety culture. Medicine in the post-Soviet countries is just beginning to explore this issue. It was difficult to involve medical workers in deliberately filling out each item in the questionnaire due to a large number of questions in their opinion. It was difficult to involve medical workers in filling out each part of the questionnaire due to a large number of questions, in their opinion.

A small number of participants are both a limitation and an advantage of this study. The advantage is that the researchers were able to communicate closely with the respondents and find out their opinion on the comprehensibility of the questions. Due to this, we have achieved the maximum completion of all questionnaire samples and prevention of negligence in the completion of the questionnaire sections in most cases.

Many hospital managers need to understand the importance of evaluating safety cultures themselves and they must be trained in this. Furthermore, the managers need to learn about methods of statistical analysis and interpretation of the results to make managerial decisions.

\section{Conclusion}

This study is dedicated to cross-cultural adaptation and validation of the "Safety LMX" tool and describes the development of a translation protocol with subsequent cognitive debriefing and field testing. This questionnaire "Safety LMX" has a wide range of possible uses, including aspects such as physical safety, psychological safety, staff training, as well as personal commitment and beliefs regarding compliance with safety principles in the workplace and in the provision of medical care to patients. The tool has good psychometric properties, which was established by the study conducted in accordance with international standards. The overall intraclass correlation coefficient of the Safety LMX questionnaire (ICC) was 0.95 $(p<0.05)$. "Test-retest" for reproducibility showed good results. Reliability factor coefficient alpha Cronbach is considered acceptable if its value for group studies is greater than or equal to 0.70 . In our study, Cronbach's alpha was 0.746 . The tool is linguistically and culturally adapted to the Russian-speaking environment and can be recommended for use in medical organizations of the Republic of Kazakhstan. The resulting Russian version of the tool could be considered a valid and reliable instrument, feasible to administer.

In most hospitals, the safety culture is not formed yet, and that safety culture required to be improved through intervention strategies. This study provides baseline data for long-term continuous assessment and a reasonable basis for further targeted actions.

\section{Authors' Contributions}

All authors have equally contributed to the intellectual content of the present paper, associated revision, and critical discussion.

\section{Acknowledgments}

The authors would like to thank all doctors who took part in the study.

\section{References}

1. Trinchero E, Farr-Wharton B, Brunetto Y; Workplace Relationships. Psychological capital. In: Accreditation and Safety Culture: A New Framework of Analysis within Healthcare Organizations, Public Organization Review. Vol. 19. Berlin: Springer; 2019. p. 139-152. https://doi.org/10.1007/ s11115-017-0390-6

2. Verbakel NJ, Langelaan M, Verheij TJ, Wagner C, Zwart DL. Effects of patient safety culture interventions on incident reporting in general practice: A cluster randomised trial. $\mathrm{Br} \mathrm{J}$ Gen Pract. 2015;65(634):e319-29. https://doi.org/10.3399/ bjgp15x684853

PMid:25918337

3. Verbano C, Turra F. A human factors and reliability approach to clinical risk management: Evidence from Italian cases. Saf Sci. 2010;48(5):625-39. https://doi.org/10.1016/j.ssci.2010.01.014

4. Institute of Medicine. To Err is Human: Building a Safer Health 
System. Washington, DC: The National Academies Press; 2000.1

5. Vries EN, Ramrattan MA, Smorenburg SM, Gouma DJ, Boermeester MA. The incidence and nature of in-hospital adverse events: A systematic review. Qual Saf Health Care. 2008;17(3):216-23. https://doi.org/10.1136/qshc.2007.023622 PMid:18519629

6. Briner M, Manser T, Kessler O. Clinical risk management in hospitals: Strategy. central coordination and dialogue as key enablers. J Eval Clin Pract. 2013;19(2):363-9. https://doi. org/10.1111/j.1365-2753.2012.01836.x

PMid:22409240

7. Awolusi IG, Marks ED. Safety activity analysis framework to evaluate safety performance in construction. J Constr Eng Manag. 2017;143(3):1-12. https://doi.org/10.1061/(asce) co.1943-7862.0001265

8. Molenaar KR, Park J, Washington S. Framework for measuring corporate safety culture and its impact on construction safety performance. J Constr Eng Manag. 2009;135(6):488-96. https:// doi.org/10.1061/(asce)0733-9364(2009)135:6(488)

9. Tam VW, Fung IW. Behavior, attitude and perception toward safety culture from mandatory safety training course. J Prof Issues Eng Educ Pract. 2012;138(3):207-13. https://doi. org/10.1061/(asce)ei.1943-5541.0000104

10. El-Jardali F, Dimassi $H$, Jamal D, Jaafar M, Hemadeh $N$. Predictors and outcomes of patient safety culture in hospitals. BMC Health Serv Res. 2011;11(1):45. https://doi. org/10.1186/1472-6963-11-45

PMid:21349179

11. Huang DT, Clermont G, Kong L, Weissfeld LA, Sexton JB, Rowan $\mathrm{KM}$, et al. Intensive care unit safety culture and outcomes: A US multicenter study. Int J Qual Health Care. 2010;22(3):151-61. https://doi.org/10.1093/intqhc/mzq017 PMid:20382662

12. Kline TJ, Willness C, Ghali WA. Determinants of adverse events in hospitals--the potential role of patient safety culture. J Healthc Qual. 2008;30(1):11-7. https://doi. org/10.1111/j.1945-1474.2008.tb01122.x PMid: 18257452

13. Yates GR, Hochman RF, Sayles SM, Stockmeier CA. Sentara Norfolk General Hospital:Accelerating improvement by focusing on building a culture of safety. Jt Comm J Qual Saf. 2004;30(10):53442. https://doi.org/10.1016/s1549-3741(04)30063-8 PMid: 15518357

14. Joint Commission International Accreditation Standards; 2017 Available from: http://www.jcrinc.com. [Last accessed on 2021 Feb 08].
15. Aiypkhanova AT. Guidance on the Interpretation of Updated Accreditation Standards for Medical Organizations Providing Outpatient Care (3 Peresmotr); 2017.

16. Beaton D, Bombardier C, Guillemin F, Ferraz MB Recommendations for the cross-cultural adaptation of the DASH and QuickDASH outcome measures. Inst Work Health. 2007;1(1):1-45.

17. Almehrizi RS. Coefficient alpha and reliability of scale scores. Appl Psychol Meas. 2013;37(6):438-59.

18. Haragus H, Deleanu B, Prejbeanu R, Timar B, Levai C, Vermesan D. Cross-cultural adaptation and validation of the Romanian hip disability and osteoarthritis outcome score for joint replacement. Int J Qual Health Care. 2018;31(4):307-11. https://doi.org/10.1093/intqhc/mzy156

PMid:30052971

19. Dauletyarova M, Semenova Y, Kaylubaeva G, Manabaeva G Khismetova Z, Akilzhanova Z, et al. Are women of east Kazakhstan satisfied with the quality of maternity care? Implementing the $\mathrm{WHO}$ tool to assess the quality of hospital services. Iran J Public Health. 2016;45(6):729-38. https://doi. org/10.3390/ijerph15020325

PMid:27648415

20. Dauletyarova MA, Semenova YM, Kaylubaeva G, Manabaeva GK, Toktabayeva B, Zhelpakova MS, et al. Are Kazakhstani women satisfied with antenatal care? Implementing the WHO tool to assess the quality of antenatal services. Int J Environ Res Public Health. 2018;15(2):325. https://doi. org/10.3390/ijerph15020325

PMid:29438330

21. Robida A. Hospital survey on patient safety culture in Slovenia: A psychometric evaluation. Int J Qual Health Care. 2013;25(4):469-75. https://doi.org/10.1093/intqhc/mzt040 PMid:23736832

22. Smits M, Dingelhoff IC, Wagner C, Wal GV, Groenewegen PP. The psychometric properties of the "hospital survey on patient safety culture" in Dutch hospitals. BMC Health Serv Res. 2008;8:230. https://doi.org/10.1186/1472-6963-8-230 PMid:18990256

23. Stoyanova R, Dimova R, Tarnovska M, Boeva T. Linguistic validation and cultural adaptation of Bulgarian version of hospital survey on patient safety culture (HSOPSC). Open Access Maced. J Med Sci. 2018;6(5):925-30. https://doi.org/10.3889/ oamjms.2018.222 PMid:29875873

24. Maroco J, Garcia-Marques T. How reliable is the alpha of Cronbach? Old issues and modern solutions? Lab Psicol. 2006;4(1):65-90. https://doi.org/10.14417//p.763 